\title{
Assessment of total arsenic and arsenic species stability in alga samples and their aqueous extracts
}

\author{
S. García Salgado, M.A. Quijano Nieto, M.M. Bonilla Simón \\ Departamento de Ingeniería Civil: Tecnología Hidráulica y Energética, Escuela Universitaria de Ingenieros Técnicos \\ de Obras Públicas, Universidad Politécnica de Madrid, Alfonso XII 3 y 5, 28014 Madrid, Spain
}

\begin{abstract}
In order to achieve reliable information on speciation analysis, it is necessary to assess previously the species stability in the sample to analyse. Furthermore, in those cases where the sample treatment for species extraction is time-consuming, an assessment of the species integrity in the extracts is of paramount importance. Thus, the present paper reports total arsenic and arsenic species stability in alga samples (Sargassum fulvellum and Hizikia fusiformis), as well as in their aqueous extracts, which were stored in amber glass and polystyrene containers at different temperatures. Total arsenic determination was carried out by inductively coupled plasma atomic emission spectroscopy (ICP-AES), after sample acid digestion in a microwave oven, while arsenic speciation was conducted by anion exchange high performance liquid chromatography on-line coupled to ICPAES, with and without sample introduction by hydride generation (HPLC-ICP-AES and HPLC-HG-ICP-AES), after aqueous microwave-assisted extraction.

The results obtained for solid alga samples showed that total arsenic (for Hijiki alga) and arsenic species present (As(V) for Hijiki and NIES No. 9 Sargasso) are stable for at least 12 months when samples are stored in polystyrene containers at $+20^{\circ} \mathrm{C}$. On the other hand, a different behaviour was observed in the stability of total arsenic and $\mathrm{As}(\mathrm{V})$ species in aqueous extracts for both samples, being the best storage conditions for Sargasso extracts a temperature of $-18{ }^{\circ} \mathrm{C}$ and polystyrene containers, under which they are stable for at least 15 days, while Hijiki extracts must be stored in polystyrene containers at $+4{ }^{\circ} \mathrm{C}$ in order to ensure the stability for 10 days.
\end{abstract}

Keywords: Alga; Arsenic stability; High performance liquid chromatography; Hydride generation; Inductively coupled plasma atomic emission spectroscopy

\section{Introduction}

Arsenic is a toxic element widely distributed in the environment, due to both natural sources and anthropogenic applications, and its speciation has received significant attention over the last years due to its species-dependent toxicity Detailed information concerning analytical methods for arsenic species determination can be found in several reviews The analytical speciation of arsenic has been generally achieved with the use of hyphenated techniques, i.e. a chromatographic system coupled to an arsenic-selective detector. Alga are considered to accumulate high percentages of arsenic, so several authors have been focused on arsenic speciation analysis in this kind of samples during the last years
The achievement of reliable results in speciation analysis requires not only sensitive techniques but also sureness of species stability. Hence, stability studies are necessary in that it is important to know with absolute certainty that there is not any species transformation during sample treatment and storage.

A number of sources can be cited as possible causes of arsenic species instability, such as chemical reactions between species, interactions with the container material, microbial activity, temperature, $\mathrm{pH}$, concentration level or light action. Therefore, it is essential to take into account the influence of these factors on species stability in order to get both a representative speciation analysis of the sample studied and an accurate assessment of the environmental problem

For arsenic analysis, contamination only occurs rarely, and events such as changes in oxidation state, changes induced by microbial activity or losses by volatilization or adsorption, have to be avoided. Several procedures are recommended for preservation of species integrity, such as freezing, cooling, acid- 
ification, sterilization, deaeration, and/or storage in the darkness. Nevertheless, there is no general agreement on these procedures. For samples where bacteria exist naturally, storage at low temperatures, or even freeze-drying, is required to prevent biological activity from modifying the sample nature

Previous studies on arsenic compounds stability has been focused mainly on water samples and inorganic arsenic forms

. Several acids (sulphuric, hydrochloric, nitric, phosphoric or ascorbic acid) have been proposed for arsenic stabilisation in water samples to reduce sample $\mathrm{pH}$ below 2 , since acidification is necessary to keep the iron in solution, which avoided co-precipitation of arsenic or adsorption onto the iron oxy-hydroxide. Furthermore, acidification allows the storage of water samples at room temperature, where inorganic arsenic species remain stable for two months, both in Pyrex and polyethylene containers. Methylarsenicals are more stable than inorganic arsenicals both in water and in urine samples In water samples, MMA and DMA have shown stability during several months, when hydrochloric acid was added

However, other authors have reported that acidification of treated wastewater samples leads to the transformation of As(III) into $\mathrm{As}(\mathrm{V})$, as well as the kinetics rise with the storage temperature . The phosphoric acid addition to preserve inorganic arsenicals has been recommended in the case of water samples with high concentration levels of iron and manganese Freezing has been reported to induce chemical changes such as precipitation of arsenic species, which were not reversed on melting. Better results were obtained when samples were stored at $+4{ }^{\circ} \mathrm{C}$. Under these conditions, As(III) and $\mathrm{As}(\mathrm{V})$ at higher concentrations $\left(20 \mu \mathrm{gL}^{-1}\right)$ were stable for about 30 days, when samples were previously filtered $(45 \mu \mathrm{m})$. Storage at higher temperatures $\left(+20\right.$ and $\left.+40^{\circ} \mathrm{C}\right)$ in the presence of light leads to oxidation processes from $\mathrm{As}(\mathrm{III})$ to $\mathrm{As}(\mathrm{V})$ and production of MMA from DMA. Flocculation, probably owing to the presence of phosphates, was also observed

The use of additives has not improved arsenic species stability in urine samples, which can be stored at low temperatures $\left(+4\right.$ and $-20^{\circ} \mathrm{C}$ ) for two months. On the other hand, the addition of $0.1 \mathrm{M} \mathrm{HCl}$ to urine samples has shown to cause relative changes in inorganic arsenic species Palacios et al. reported transformations of $\mathrm{As}(\mathrm{III})$ and $\mathrm{AsC}$ species in untreated urine samples by oxidation to As(V) and AsB species, respectively. Arsenic species stability in urine samples improved, for at least 67 days at ambient temperature or $+4{ }^{\circ} \mathrm{C}$, when samples are treated to obtain a clean-up dry residue.

Regarding solid samples, stability studies have been performed mainly on aqueous extracts. Pizarro et al. reported that arsenic species in (1:1) methanol water extracts from rice remained stable for at least three months, whereas in fish and chicken tissue extracts, AsB was transformed into DMA over time. On the other hand, methylarsenicals compounds were stable in phosphoric acid extracts from soils, whereas As(III) oxidised to As(V). Furthermore, arsenite in phosphoric-ascorbic acid extracts from contaminated soil samples was also observed to be unstable

Recovery studies should be also considered in order to assess the arsenic species stability during extraction and chromatogra- phy steps . Since arsenic species stability is dependent on the matrix, concentration level and the treatment followed for sample analysis, it is necessary to perform stability studies for each case.

This work focuses on total arsenic and arsenic species stability in alga samples and their aqueous extracts. Storage temperature and container material were assessed. Losses, species transformations and matrix influence were studied. Stability tests on aqueous extracts obtained from alga samples allowed us to know the period of time during which extracts integrity can be maintained, in order to avoid the immediate analysis.

\section{Experimental}

\subsection{Instrumentation}

A MARS 5 Microwave oven (CEM, Matthews, NC, USA) was used for digestion and extraction of the samples. The temperature was monitored in a control vessel by an armoured fibre-optic temperature control probe. The reaction vessels used were made of Teflon for digestion and Pyrex for extraction procedures, respectively.

An Eppendorf centrifuge 5804 R (Hamburg, Germany) was used for the centrifugation of the alga extracts.

$0.45 \mu \mathrm{m}$ Millipore nylon filters were used to filter all the HPLC solutions, as well as $0.20 \mu \mathrm{m}$ Millex syringe filters to filter the alga extracts before their injection in the HPLC system.

The inductively coupled plasma atomic emission spectrometry instrument used was a Liberty Series II Axial Sequential ICP-AES (Varian Australia, Mulgrave, Australia). The hydride generation system used was a VGA-77 unit (Varian). Before coupling the chromatographic system, the ICP-AES working conditions were optimised using a standard solution containing $1.0 \mathrm{mg} \mathrm{L}^{-1}$ of manganese. The arsenic signal was then optimised using a $1.0 \mathrm{mg} \mathrm{L}^{-1}$ arsenate standard solution for subsequent HPLC-ICP-AES experiments and a $0.1 \mathrm{mg} \mathrm{L}^{-1}$ arsenite standard solution when the hydride generation system was coupled.

The chromatographic system consisted of a Jasco PU-980 HPLC pump (Jasco, Tokyo, Japan) with a Rheodyne 7725 six-port sample injection valve fitted with a $100 \mu \mathrm{L}$ sample loop (Rheodyne, CA, USA). Separations were carried out in a Hamilton PRP-X100 $(250 \mathrm{~mm} \times 4.1 \mathrm{~mm}, 10 \mu \mathrm{m})$ (Phenomenex, Torrance, CA, USA) anion exchange column. A guard column Hamilton PRP-X100 (25 $\mathrm{mm} \times 2.3 \mathrm{~mm}, 12-20 \mu \mathrm{m})$ (Phenomenex) was used in order to preserve the analytical column.

The chromatographic system was then coupled to the ICPAES instrument by a polytetrafluoroethylene capillary tube ( $20 \mathrm{~cm}, 0.5 \mathrm{~mm}$ I.D.), which connected the column outlet to the Meinhard nebuliser inlet. When the hydride generation unit was used, the chromatographic system was coupled to the hydride generation unit by the same capillary tube, running from the column outlet to the hydride generation unit inlet.

Chromatographic signals were registered using a Star 800 module interface box and processed using the Star software (Varian). Signal quantification was carried out in the peak area mode. 


\subsection{Reagents and standard solutions}

Stock solutions of $1000 \mathrm{mg} \mathrm{L}^{-1}$ arsenic were prepared by dissolving the respective amount of the pure compound in deionised water (Milli-Q system, Millipore, USA). As(III) and $\mathrm{As}(\mathrm{V})$ standards solutions were prepared from $\mathrm{NaAsO}_{2}$ and $\mathrm{Na}_{2} \mathrm{HAsO}_{4}$, respectively (Panreac, Barcelona, Spain), MMA from $\mathrm{CH}_{3} \mathrm{AsO}_{3} \mathrm{Na}_{2}$ (Supelco, Bellefonte, PA, USA) and DMA from $\left(\mathrm{CH}_{3}\right)_{2} \mathrm{AsNaO}_{2} \cdot 3 \mathrm{H}_{2} \mathrm{O}$ (Fluka, Neu Ulm, Germany). The stock solutions were kept at $+4{ }^{\circ} \mathrm{C}$ in the darkness. Working solutions were prepared daily and then diluted with deionised water to the final concentration.

The eluent used for the chromatographic separations was phosphate buffer ( $\mathrm{pH} 5.5$ ) at a concentration of $17 \mathrm{mM}$. It was prepared by mixing independent solutions of $\left(\mathrm{NH}_{4}\right)_{2} \mathrm{HPO}_{4}$ and $\left(\mathrm{NH}_{4}\right) \mathrm{H}_{2} \mathrm{PO}_{4}$ (Fluka, Neu Ulm, Germany) until the desired $\mathrm{pH}$ was reached.

All HPLC solutions were filtered and degassed before use.

Nitric acid 69.5\% (Scharlau, Barcelona, Spain) was used to digest the samples.

Sodium borohydride solution $0.5 \%(\mathrm{w} / \mathrm{v})$ was prepared by dissolving $\mathrm{NaBH}_{4}$ powder (Aldrich, Milwaukee, WI, USA) of 98\% purity in deionised water and stabilising it with $0.5 \%(\mathrm{w} / \mathrm{v})$ sodium hydroxide (Fluka, Neu Ulm, Germany). The resulting solution was filtered and kept at $+4{ }^{\circ} \mathrm{C}$ in the darkness. Hydrochloric acid solution (4.0 M) was prepared by dilution of $\mathrm{HCl} 37 \%$ (Scharlau, Barcelona, Spain).

\subsection{Alga samples}

The reference material NIES No. 9, certified for total arsenic $\left(115 \pm 9 \mu \mathrm{g} \mathrm{g}^{-1}\right)$, was a lyophilised Sargasso material (Sargassum fulvellum), purchased from National Institute for Environmental Studies (Tsukuba, Ibaraki, Japan). The alga sample Hijiki (Hizikia fusiformis) was acquired in food Spanish markets as dry material, grinded in a mill to a particle size of $125 \mu \mathrm{m}$, and stored in a polystyrene container at $+20^{\circ} \mathrm{C}$.

The alga samples selected for the stability study have been thoroughly studied . Hijiki alga was selected due to its similarity to the certified reference material (Sargasso), in terms of total arsenic content and arsenic species present (As(V)) in both samples.

\subsection{Procedures}

\subsubsection{Sample treatment}

Total arsenic content in alga samples was determined by ICPAES following the microwave digestion method described in a previous work [10]. The results obtained for five replicates were $106 \pm 6$ and $88 \pm 6 \mu \mathrm{g} \mathrm{g}^{-1}$ of arsenic for NIES No. 9 and Hijiki samples, respectively.

For arsenic species extraction, approximately $200 \mathrm{mg}$ of alga sample were accurately weighed into a Pyrex vessel and $8 \mathrm{ml}$ of deionised water were added. The vessel was introduced in the microwave-assisted extraction system and a temperature of $90^{\circ} \mathrm{C}$ was applied for $5 \mathrm{~min}$. Then, the extract obtained was centrifuged for $10 \mathrm{~min}$ at $14000 \mathrm{~g}$. This extraction process was
Table 1

ICP-AES, hydride generation and chromatographic operating conditions

\begin{tabular}{ll}
\hline ICP-AES & \\
Forward power & $1200 \mathrm{~W}$ \\
Photomultiplier tube voltage & $650 \mathrm{~V}$ \\
Nebulisation argon pressure & $180 \mathrm{kPa}^{-1}$ \\
Auxiliary argon flow rate & $1.50 \mathrm{~L} \mathrm{~min}^{-1}$ \\
Coolant argon flow rate & $15.0 \mathrm{~L} \mathrm{~min}^{-1}$ \\
Nebuliser type & Meinhard concentric glass \\
Hydride generation system & \\
Acid solution & $4 \mathrm{M} \mathrm{HCl}$ \\
Reductant solution & $0.5 \%(\mathrm{w} / \mathrm{v}) \mathrm{NaBH}_{4}(\mathrm{stabilised}$ with \\
& $0.5 \%(\mathrm{w} / \mathrm{v}) \mathrm{NaOH})$ \\
Carrier argon pressure & $350 \mathrm{kPa}$ \\
Chromatographic system & \\
Guard column & $\mathrm{Hamilton} \mathrm{PRP-X100}$ \\
& $(25 \mathrm{~mm} \times 2.3 \mathrm{~mm}, 12-20 \mu \mathrm{m})$ \\
Analytical column & $\mathrm{Hamilton} \mathrm{PRP-X100}$ \\
& $(250 \mathrm{~mm} \times 4.1 \mathrm{~mm}, 10 \mu \mathrm{m})$ \\
Mobile phase & Phosphate buffer $17 \mathrm{mM}$ at pH 5.5 \\
Flow rate & $1.0 \mathrm{~mL} \mathrm{~min}^{-1}$ \\
Injection volume & $100 \mu \mathrm{l}$
\end{tabular}

repeated three times. The supernatants were mixed and diluted up to $25 \mathrm{~mL}$ with deionised water. The concentration of total arsenic extracted was determined by ICP-AES.

Prior to the chromatographic analysis, final extracts were filtrated with $0.20 \mu \mathrm{m}$ Millex syringe filters. The arsenic species studied (As(III), As(V), MMA and DMA) were separated and detected by HPLC-HG-ICP-AES, using the operation conditions given in Table 1. All the extracts were also analysed by HPLC-ICP-AES, in order to check the absence of other arsenic species, different to those studied, in the samples. The analytical peaks obtained were evaluated in terms of peak area by external calibration at $193.696 \mathrm{~nm}$ line. The instrument drift was checked by injection of a standard solution every two samples injections.

The chromatographic profiles obtained by HPLC-ICP-AES and HPLC-HG-ICP-AES for standard solutions and the aqueous extracts from Sargasso and Hijiki alga, are shown in previous papers with references and , respectively, as well as the analytical characteristics of both methods.

The arsenic species stability during the extraction method was confirmed by further experiments on spiked alga samples, due to the absence of reference materials certified for arsenic species, in a previous work

\subsubsection{Design of the stability study}

The storage containers used for stability tests on aqueous extracts and dry samples were $12 \mathrm{~mL}$ vials of amber glass and polystyrene and $60 \mathrm{~mL}$ polystyrene containers, respectively. Containers were previously washed with deionised water, immersed in a $5 \% \mathrm{HNO}_{3}$ bath for $24 \mathrm{~h}$, and finally rinsed with deionised water before use.

2.4.2.1. Stability test on dry alga samples. For the stability test performed on dry alga samples, different portions of the solid were placed, previous homogenisation by manual shaking for $10 \mathrm{~min}$, in $60 \mathrm{~mL}$ polystyrene containers, which were sealed 
with parafilm and maintained in the darkness at $+20^{\circ} \mathrm{C}$. The reference concentration values $\left(C_{\text {ref }}\right)$ of total arsenic and arsenic species identified in the sample were evaluated by ten independent analyses prior to the beginning of the stability test. The stability study measurements were performed after 1, 7, 15, 30, 90, 180 and 365 days, preparing the sample for total arsenic determination and arsenic speciation immediately before the measurement. Only arsenic species stability test was carried out on the lyophilised Sargasso NIES No. 9, since this reference material is certified for total arsenic even though no information on species concentration and stability is available.

2.4.2.2. Stability test on alga aqueous extracts. The stability test on aqueous extracts was performed as follows: 24 alga sample portions of approximately $200 \mathrm{mg}$ were processed following the extraction method specified in Section 2.4.1 (Sample treatment), from Section 2.4 (Procedure). The aqueous extracts obtained were mixed and placed into 30 polystyrene and 30 amber glass vials, which were sealed with parafilm until analysis. 15 vials of each container material were maintained in the darkness at -18 and $+4{ }^{\circ} \mathrm{C}$. A total of 60 vials were prepared to be stored under each experimental condition, and each vial was used only once. Once the samples were prepared and stored under the different conditions, three vials of each type were analysed after $1,4,7,10$ and 15 days, respectively. The reference concentration values $\left(C_{\text {ref }}\right)$ were obtained from ten measurements of three different vials after sample preparation.

\section{Results and discussion}

The stability $R_{\mathrm{X}}$, expressed as a percentage, was evaluated as the ratio of the average of three concentration measurements made under each storage condition $\left(C_{\mathrm{x}}\right)$ to the mean value $\left(C_{\mathrm{ref}}\right)$ of ten different measurements made at reference time $(t=0)$, as follows

$R_{X}=\frac{C_{X}}{C_{\text {ref }}} \times 100$

The uncertainty $U_{x}$ in the ratio $R_{x}$ was obtained from the coefficient of variation of each set of measurements according to the following expression

$U_{X}=\sqrt{\left(C V_{X}^{2}+C V_{\text {ref }}^{2}\right)} \times R_{X}$

where $C V_{x}$ is the coefficient of variation of three independent measurements under each storage condition and $C V_{\text {ref }}$ is the coefficient of variation obtained for the reference conditions.

In the case of ideal stability, $R_{x}$ should be $100 \%$, but in practice there are random variations due to the uncertainty in the measurements because of the standard deviation observed. Therefore, the value $R_{x}$ should be between the limits [100- $U_{x}$ ] and $\left[100+U_{x}\right]$ to conclude the species stability

\subsection{Stability tests on dry alga samples}

Total arsenic and arsenic species stability was determined in Hijiki alga sample. In the reference material of lyophilised

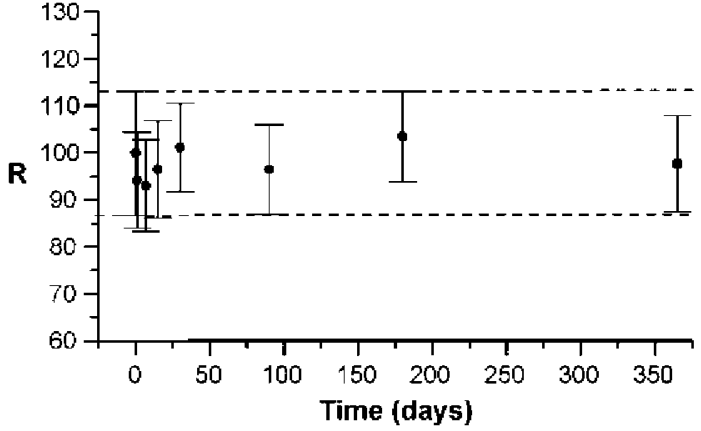

Fig. 1. Total As stability in Hijiki dry alga stored at $+20^{\circ} \mathrm{C}$ in polystyrene containers; dots: stability $R_{x} ; I$ uncertainty for each point $U_{x}$; dashes: uncertainty associated with $t=0$ days.

Sargasso, only the arsenic species stability test was performed. Both samples were analysed immediately after reception. The reference concentration value, $C_{\text {ref }}(t=0$ days, $n=10)$ used in the stability test, of total arsenic for Hijiki sample was $86 \pm 8 \mu \mathrm{gg}^{-1}$, while the reference concentration values of $\mathrm{As}(\mathrm{V})$ species for Sargasso and Hijiki samples were $73 \pm 4$ and $62 \pm 3 \mu \mathrm{gg}^{-1}$, respectively.

The results obtained for total arsenic in Hijiki alga after 1 , 7, 15, 30, 90, 180 and 365 days are given in Fig. 1, and show that total arsenic in the dry material is stable when the sample is stored in polystyrene containers at $+20^{\circ} \mathrm{C}$, for at least one year.

Fig. 2 shows the results obtained for the arsenic species found, which is As(V), in Sargasso (Fig. 2a) and Hijiki (Fig. 2b) samples. This study was performed during the same time period and under the same storage conditions as in the total arsenic study. The results allow us to conclude that the identified arsenic
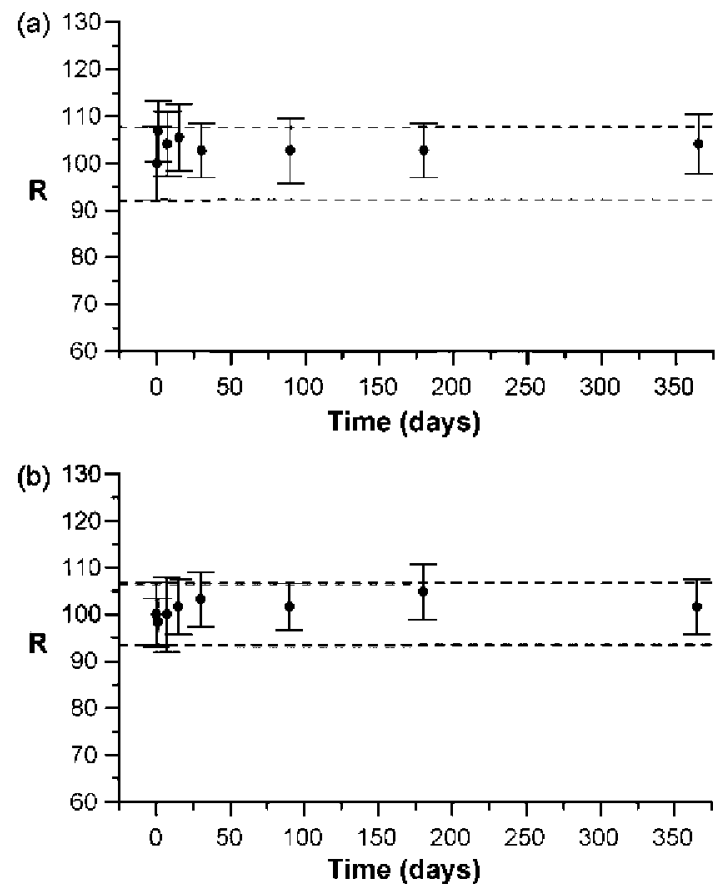

Fig. 2. As(V) species stability in (a) lyophilised Sargasso and (b) dry Hijiki stored at $+20^{\circ} \mathrm{C}$ in polystyrene containers. 
species is stable when samples are stored in polystyrene containers at $+20^{\circ} \mathrm{C}$, for at least one year.

Therefore, the storage of the dry material could be carried out without any special consideration, in polystyrene containers at $+20^{\circ} \mathrm{C}$

\subsection{Stability tests on aqueous extracts}

The total arsenic stability test on the aqueous extracts from Sargasso and Hijiki algae were carried out under the conditions indicated in the above section. The temperature of $+20^{\circ} \mathrm{C}$ was excluded in order to avoid the microbiological activity,
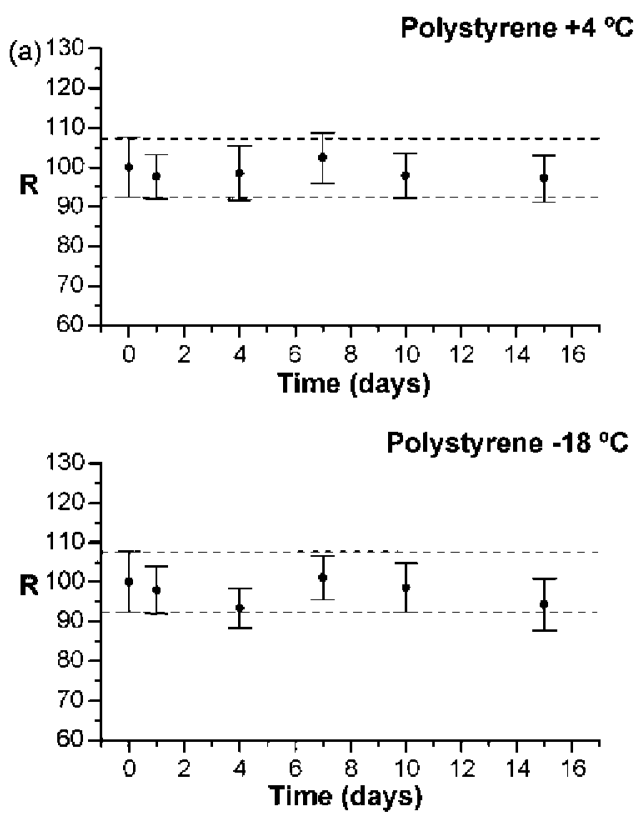

(b)
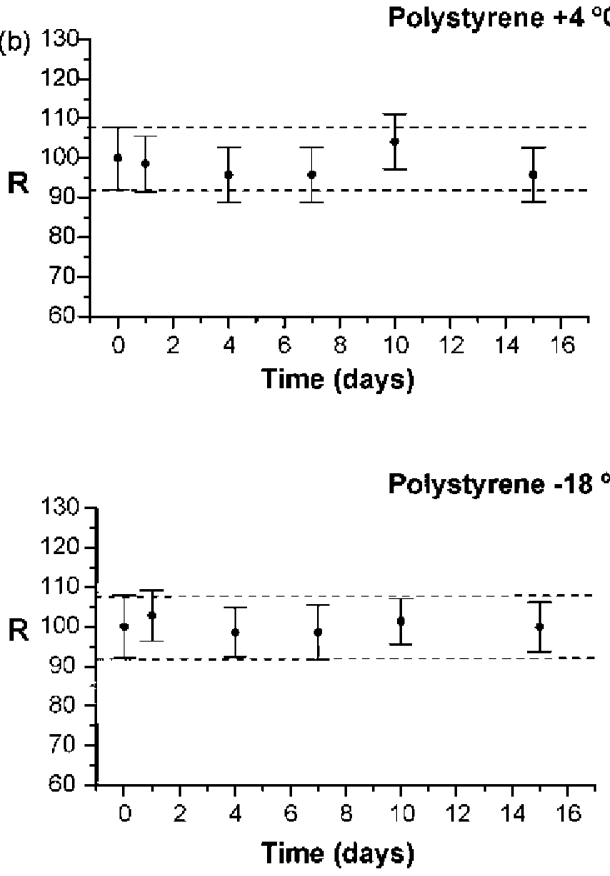

which may cause sample decomposition. The stability study was limited to 15 days in that the decomposition of the aqueous extracts was observed. The reference concentration values, $C_{\text {ref }},(t=0$ days, $n=10)$ of total arsenic and $\mathrm{As}(\mathrm{V})$ species found in the aqueous extracts from Sargasso sample were $94 \pm 5$ and $72 \pm 4 \mu \mathrm{g} \mathrm{g}^{-1}$, respectively, while those found in Hijiki aqueous extracts were $72 \pm 4$ and $62 \pm 7 \mu \mathrm{g} \mathrm{g}^{-1}$, respectively.

The results obtained (Fig. 3) show that total arsenic in the aqueous extracts from Sargasso (Fig. 3a) and Hijiki (Fig. 3b) samples stored at $-18{ }^{\circ} \mathrm{C}$ in polystyrene containers, as well as at $+4^{\circ} \mathrm{C}$ in both kind of containers, is stable for at least 15 days, in spite of the decomposition of the extracts observed at $+4{ }^{\circ} \mathrm{C}$
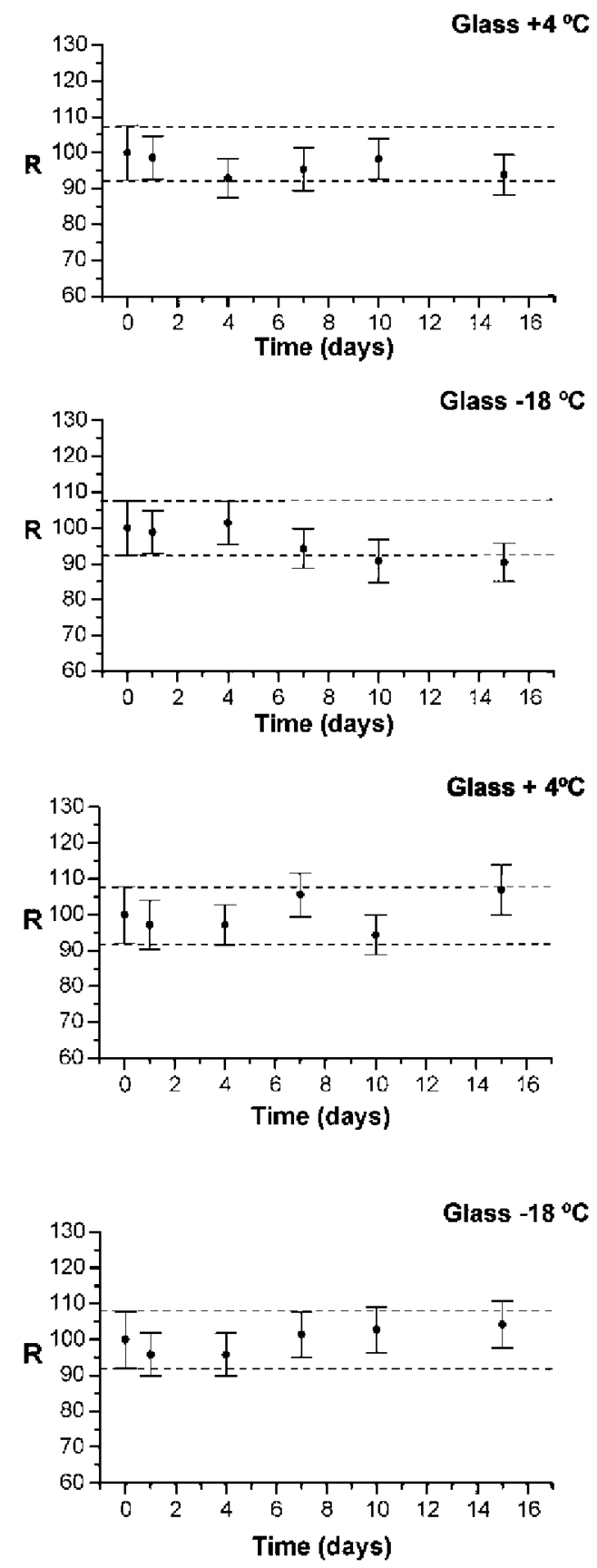

Fig. 3. Total As stability in the aqueous extracts from (a) Sargasso and (b) Hijiki stored at +4 and $-18^{\circ} \mathrm{C}$ in polystyrene and amber glass containers. 
since the 10th day of storage. However, a different behaviour was observed in glass containers at $-18^{\circ} \mathrm{C}$ for both samples studied. Thus, total arsenic remains stable in the aqueous extracts from Hijiki alga, while significant losses were observed in Sargasso extracts, so the stability can only be ensured for 7 days in the extracts stored under these conditions.

Fig. 4 shows the results of the stability test obtained for the species As(V) in the aqueous extracts of Sargasso (Fig. 4a) and Hijiki (Fig. 4b) samples.

The results obtained for Sargasso extracts (Fig. 4a) show that As(V) species remains stable for at least 15 days when extracts are stored in polystyrene at both temperatures tested. However, in amber glass containers $\mathrm{As}(\mathrm{V})$ remains stable at $-18^{\circ} \mathrm{C}$, while significant losses are observed at $+4^{\circ} \mathrm{C}$ after 10 days of storage.
Therefore, a relation between the stability of total arsenic and As(V) species present in Sargasso extracts stored in glass containers was not found. Total arsenic losses observed at $-18^{\circ} \mathrm{C}$ and $\mathrm{As}(\mathrm{V})$ species stability at this same temperature may be associated with precipitation or adsorption processes of different arsenic species, which were not reversed on melting

On the other hand, As(V) species instability observed at $+4^{\circ} \mathrm{C}$ can not be related to similar processes, due to total arsenic stability observed under these conditions. Furthermore, since any new peak was not detected in the chromatograms by HPLCICP-AES and HPLC-HG-ICP-AES, a species transformation cannot be confirmed. However, As(V) species instability is coincident with the extract decomposition, which leads us to think that a fraction of this species may be transformed or captured (a)
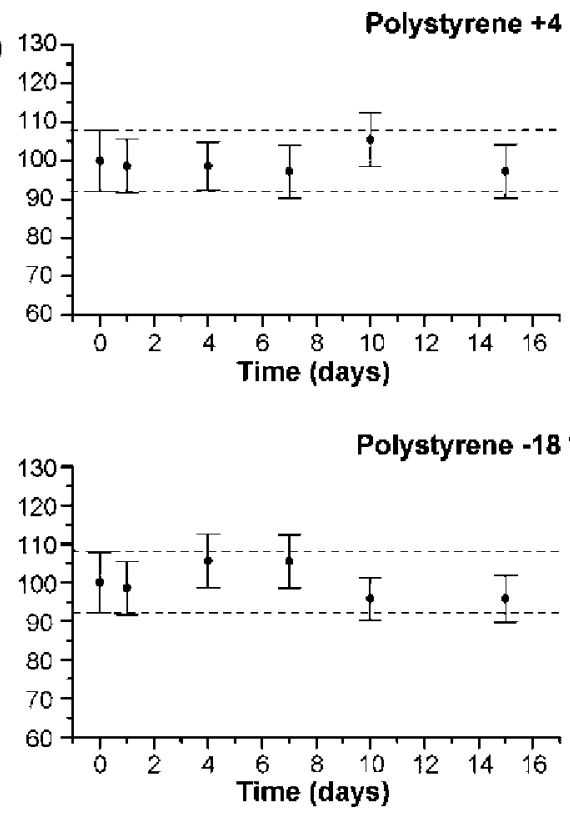

(b)
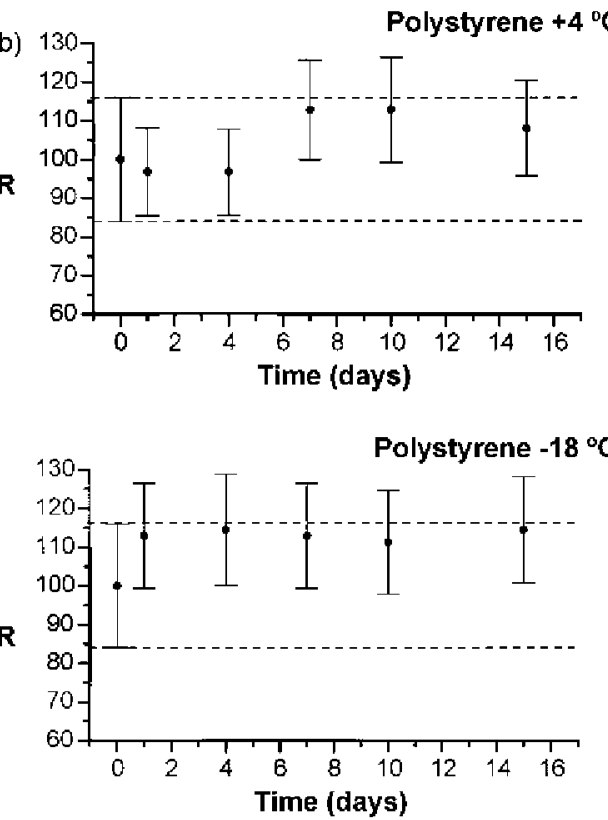

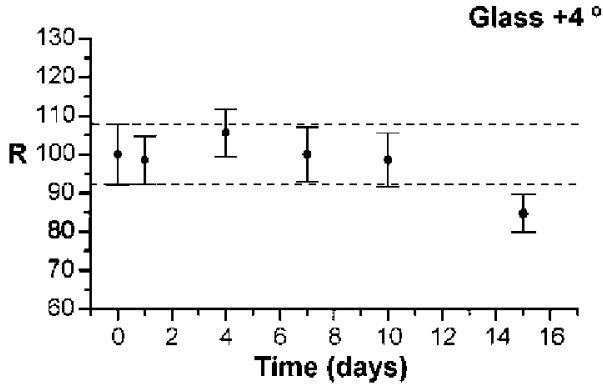

Glass $-18{ }^{\circ} \mathrm{C}$
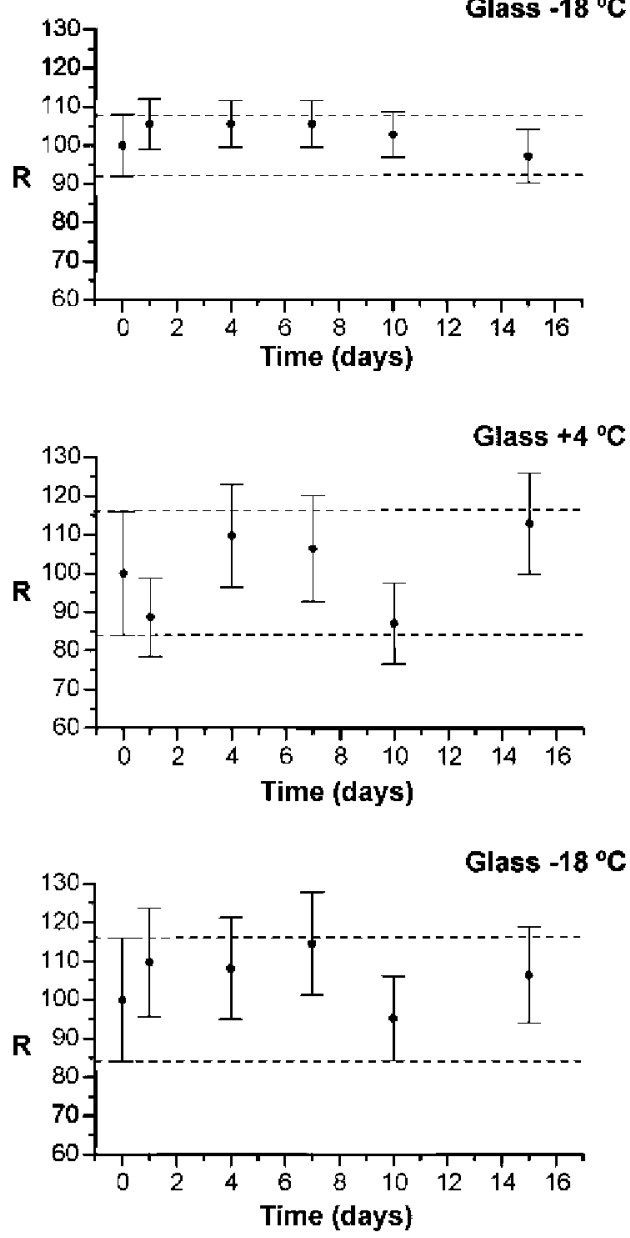

Fig. 4. As(V) stability in the aqueous extracts from (a) Sargasso and (b) Hijiki stored at +4 and $-18^{\circ} \mathrm{C}$ in polystyrene and amber glass containers. 


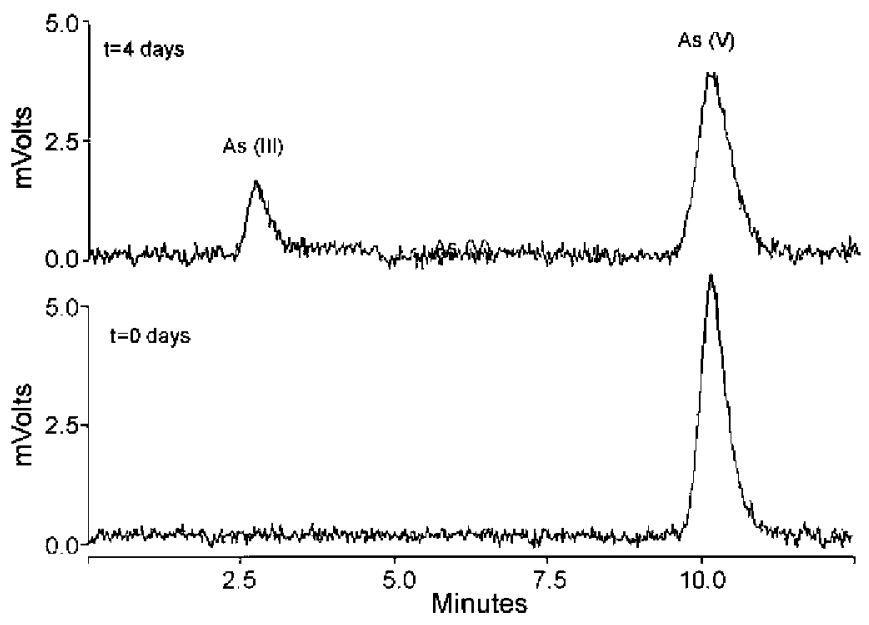

Fig. 5. HPLC-HG-ICP-AES chromatogram obtained for aqueous extracts from Hijiki stored at $-18^{\circ} \mathrm{C}$ in polystyrene containers at the 4 th day of storage, compared to the reference chromatogram ( $t=0$ days).

as a complex form, which can be retained in any step of the chromatographic method.

The results obtained for Hijiki extracts (Fig. 4b) show that $\mathrm{As}(\mathrm{V})$ species remains stable for at least 15 days at both temperatures tested and in both types of containers. However, in Hijiki extracts stored at $-18^{\circ} \mathrm{C}$ and in both types of containers tested, the appearance of As(III) species was observed since the 4th day of storage (Fig. 5). The concentration of As(III) found in the extracts stored in both amber glass and polystyrene containers was about $(3.4 \pm 1.5) \mu \mathrm{gg}^{-1}$, and remained stable for the remaining time of the study. The species As(III) appearance is not the result of the transformation of $\mathrm{As}(\mathrm{V})$, since losses of this species were not observed. Furthermore, reduction reactions are not liable to occur in aqueous solutions without deaeration. It is more likely that As(III) species comes from the transformation or release from non-detectable arsenic species present in the extract by the chromatographic method used.

\section{Conclusions}

The results obtained for the stability tests on solid alga samples (lyophilised Sargasso and dry Hijiki) show that transport and storage of these materials can be carried out at room temperature using polystyrene containers. Furthermore, they show that it is not necessary to carry out the lyophilisation of the sample in order to enhance its stability.

Regarding the aqueous extracts, different results were found for both samples. The optimum storage conditions for Sargasso extracts consist of using polystyrene containers and a temperature of $-18^{\circ} \mathrm{C}$, under which both total arsenic and $\mathrm{As}(\mathrm{V})$ species remain stable for at least 15 days. However, Hijiki extracts can be stored in the same type of containers at $+4{ }^{\circ} \mathrm{C}$ for a maximum of 10 days.
The differences observed in both samples studied show the influence of sample matrix on the stability of total arsenic and arsenic species. This fact emphasizes the necessity of conducting stability studies on each kind of sample studied.

\section{Acknowledgement}

The authors would like to thank to 'Ministerio de Ciencia y Tecnología' (project FEDER UPM00-33015), and to 'Universidad Politécnica de Madrid’ (project CCG06-UPM/QMC-223) for financial support.

\section{References}

S. Karthikeyan, S. Hirata, Appl. Organomet. Chem. 18 (2004) 323.

Z. Gong, X. Lu, M. Ma, C. Watt, X.C. Le, Talanta 58 (2002) 77.

S. McSheehy, J. Szpunar, R. Morabito, Ph. Quevauviller, Trends Anal. Chem. 22 (2003) 191

J. Szpunar, Analyst 125 (2000) 963.

G. Raber, K.A. Francesconi, K.J. Irgolic, W. Goessler, Fresenius J. Anal. Chem. 367 (2000) 181.

R. Tukai, W.A. Maher, I.J. McNaught, M.J. Ellwood, Anal. Chim. Acta 457 (2002) 173.

W. Li, C. Wei, C. Zhang, M. Van Hulle, R. Cornelis, X. Zhang, Food Chem. Toxicol. 41 (2003) 1103.

E. Schmeisser, W. Goessler, N. Kienzl, K.A. Francesconi, Anal. Chem. 76 (2004) 418 .

O. Muniz-Naviero, A. Moreda-Pineiro, A. Bermejo-Barrera, P. BermejoBarrera, At. Spectrose. 25 (2004) 79.

S. García Salgado, M.A. Quijano Nieto, M.M. Bonilla Simón, Talanta 68 (2006) 1522.

S. García Salgado, M.A. Quijano Nieto, M.M. Bonilla Simón, J. Chromatogr. A 1129 (2006) 54.

J.L. Gómez Ariza, E. Morales, D. Sánchez-Rodas, I. Giráldez, Trends. Anal. Chem. 19 (2000) 200.

M. Leermakers, W. Baeyens, M. De Gieter, B. Smedts, C. Meert, H.C. De Bisschop, R. Morabito, P. Quevauviller, Trends. Anal. Chem. 25 (2006) 1.

G.E.M. Hall, J.C. Pelchat, G. Gauthier, J. Anal. At. Spectrom. 14 (1999) 205.

L.F. Braña, F. Sánchez, M.A. Palacios, M.M. Bonilla, R. Torralba, Química Analítica 20 (2002) 181.

M. Segura, J. Muñoz, Y. Madrid, C. Cámara, Anal. Bioanal. Chem. 374 (2002) 513.

B. Daus, H. Weiss, J. Mattusch, R. Wennrich, Talanta 69 (2006) 430 .

J. Feldmann, V.W.-M. Lai, W.R. Cullen, M. Ma, X. Lu, X.C. Le, Clin. Chem. 45 (1999) 1988.

M.A. Palacios, M. Gómez, C. Cámara, M.A. López, Anal. Chim. Acta 340 (1997) 209.

I. Pizarro, M. Gómez, C. Cámara, M.A. Palacios, Anal. Chim. Acta 495 (2003) 85 .

M.J. Ruiz-Chancho, J.F. López-Sánchez, R. Rubio, Anal. Bioanal. Chem. 387 (2007) 627 .

K.A. Francesconi, D. Kuehnelt, Analyst 129 (2004) 373.

M. Segura, Y. Madrid, C. Cámara, C. Rebollo, J. Azcárate, G. Kramer, Ph. Quevaullier, J. Environ. Monit. 2 (2000) 576.

P. Moreno, M.A. Quijano, A.M. Gutiérrez, M.C. Pérez-Conde, C. Cámara, Anal. Bioanal. Chem. 374 (2002) 466. 